\title{
EFFECTS OF MICROSTRUCTURE ON THE HIGH TEMPERATURE CONSTITUTIVE BEHAVIOR OF IN100
}

\author{
W.W. Milligan ${ }^{1}$, E.L. Orth ${ }^{1}$, J.J. Schirra ${ }^{2}$, M.F. Savage ${ }^{2}$ \\ ${ }^{1}$ Michigan Technological University, Department of Materials Science and Engineering, Houghton, MI 49931, USA \\ ${ }^{2}$ Pratt and Whitney, 400 Main St MS 114-40, East Hartford, CT 06108, USA
}

Keywords: Nickel alloys, constitutive modeling, deformation, precipitation hardening

\begin{abstract}
An experimental program was conducted in order to determine the effects of microstructure on the high temperature constitutive behavior or powder-processed IN100. The relevant application is the high pressure turbine disk in a gas turbine engine. Eight different microstructures were prepared, with $260^{\circ} \mathrm{C}$ yield strengths ranging from 945 to $1165 \mathrm{MPa}$. For each microstructure, tensile tests and cyclic constitutive tests were conducted at $260^{\circ} \mathrm{C}$ and $650^{\circ} \mathrm{C}$. This paper reports on the tensile test results. The tensile curves were fit to a modified RambergOsgood constitutive model, which contains four material constants. It was found that two of the constants were sensitive to microstructure, while two others were not. The constant $\mathrm{K}_{1}$, which is analogous to the strength coefficient in the traditional power-law hardening expression, varied in exactly the same way as the yield strength. The variations in yield strength and $\mathrm{K}_{1}$ were consistent with the Huther-Reppich strength model, with the secondary $\gamma^{\prime}$ size being the dominant microstructural term. There was also a smaller effect of tertiary $\gamma^{\prime}$ and grain size. The hardening exponent $\mathrm{n}$, which is basically the inverse of the hardening exponent in the traditional power-law hardening expression, was sensitive to secondary $\gamma^{\prime}$ size and also to the presence of primary $\gamma^{\prime}$, but not to grain size.
\end{abstract}

\section{Introduction}

Constitutive modeling is utilized by engine designers to predict stresses and strains in turbine engine components. It is also used for life prediction purposes, making it one of the key technologies in the industry. Current constitutive models are basically empirical, and are essentially developed from simple curve fits of test data and macroscopic continuum-mechanical models.

It would be highly desirable to have some knowledge of the microstructure in the constitutive models, so materials science could be used concurrently with engineering design to promote more efficient and capable engines. For example, if the designer knew the effect of changing the grain size or the secondary $\gamma^{\prime}$ size on the constitutive behavior, he or she could propose new heat treatments or other processing steps to help solve a fatigue problem in a component

In order to explore this concept, a substantial experimental program was undertaken to determine microstructural effects on constitutive behavior in powder-processed IN100, a standard turbine disk alloy. The alloy contains $60 \% \gamma^{\prime}$, and can be used in a sub-solvus or a super-solvus form, depending on the design criteria.

\section{Materials}

The baseline material for this study is a sub-solvus processed IN100 which was prepared by powder metallurgy techniques. Powders were consolidated by extrusion. The extrusions were subsequently forged, solution treated, and aged by proprietary processes. The alloy composition is listed in Table I. The material contains relatively large primary $\gamma^{\prime}$ which is not dissolved during the solutionizing step, as well as secondary and tertiary $\gamma^{\prime}$ particles which form during cooling and subsequent carbide stabilization and aging treatments. The details of the heat treatment process are proprietary. The $\gamma$ matrix grain size is relatively fine, at 3-5 $\mu \mathrm{m}$. A typical microstructure is presented in Figure 1, which shows the matrix grains and the primary $\gamma^{\prime}$ particles.

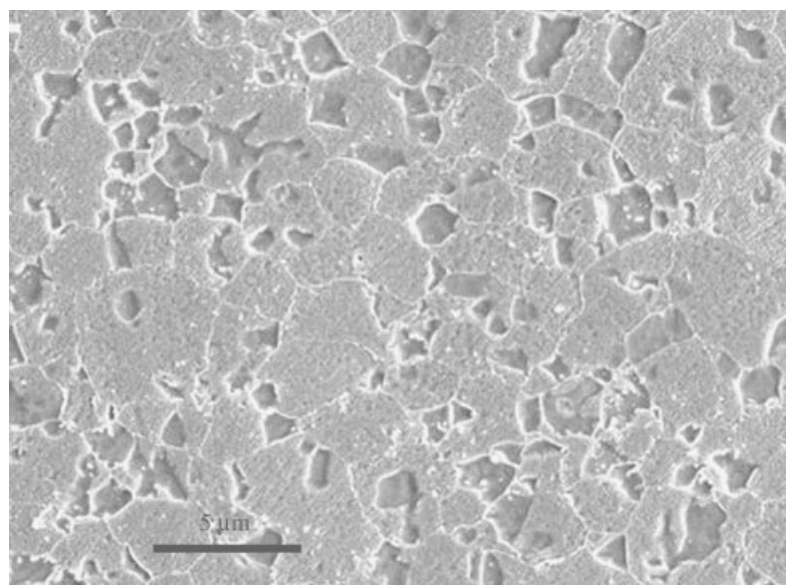

Figure 1. Scanning electron micrograph of the baseline IN100 microstructure produced by sub-solvus heat treatment. The large, globular particles are the primary $\gamma^{\prime}$.

By varying the solution heat treatment temperature and cooling rate after the solutionizing step, it was possible to produce different grain sizes, as well as different sizes and distributions of the three classes of $\gamma^{\prime}$ precipitates.

In order to study the fundamentals of deformation and mechanical behavior, it was desirable to produce materials that represent the "matrix" seen in Figure 1. (That is, the IN100 alloy composition after subtracting out the primary $\gamma^{\prime}$ particles.) This was done in support of a finite element study which treated the primary $\gamma^{\prime}$ and the "matrix" as a composite structure. It was also intended to study the effects of the primary $\gamma^{\prime}$ on the constitutive behavior of the alloy. 
Table I- Alloys compositions (weight percent)

\begin{tabular}{|l|c|c|c|c|c|c|c|c|c|c|c|c|}
\hline & $\mathrm{Al}$ & $\mathrm{Ti}$ & $\mathrm{Cr}$ & $\mathrm{Co}$ & $\mathrm{Mo}$ & $\mathrm{V}$ & $\mathrm{Fe}$ & $\mathrm{C}$ & $\mathrm{B}$ & $\mathrm{Zr}$ & $\mathrm{Y}$ & $\mathrm{Ni}$ \\
\hline IN100 & 4.9 & 4.3 & 12.3 & 18.3 & 3.3 & 0.7 & 0.1 & 0.06 & 0.02 & 0.02 & & bal \\
\hline Matrix Alloy & 4.5 & 3.6 & 14.5 & 20.0 & 3.6 & 0.7 & 0.1 & 0.08 & 0.02 & 0.02 & 0.07 & bal \\
\hline
\end{tabular}

Table II- Microstructures and strengths

\begin{tabular}{|c|c|c|c|c|c|c|c|c|}
\hline \multirow[t]{2}{*}{ Material } & \multicolumn{2}{|c|}{ Primary $\gamma^{\prime}$} & \multicolumn{2}{|c|}{ Secondary $\gamma$} & \multicolumn{2}{|c|}{ Tertiary $\gamma^{\prime}$} & \multirow{2}{*}{$\begin{array}{c}\gamma \text { Grain size } \\
(\mathrm{GS}) \\
\mu \mathrm{m}\end{array}$} & \multirow{2}{*}{$\begin{array}{c}260^{\circ} \mathrm{C} \text { yield } \\
\text { strength, } \mathrm{MPa}\end{array}$} \\
\hline & $\begin{array}{l}\text { Size } \\
\left(d_{1}\right) \\
\mu \mathrm{m}\end{array}$ & $\begin{array}{c}\text { Fraction } \\
\left(f_{1}\right)\end{array}$ & $\begin{array}{l}\text { Size } \\
\left(d_{2}\right) \\
n m\end{array}$ & $\begin{array}{c}\text { Fraction } \\
\left(f_{2}\right)\end{array}$ & $\begin{array}{l}\text { Size } \\
\left(d_{3}\right) \\
n m\end{array}$ & $\begin{array}{c}\text { Fraction } \\
\quad\left(f_{3}\right)\end{array}$ & & \\
\hline Sub 1 & 1.28 & 0.25 & 109 & 0.32 & 21 & 0.024 & 4.2 & 1165 \\
\hline Sub 2 & 1.43 & 0.22 & 152 & 0.34 & 10 & 0.042 & 3.6 & 1048 \\
\hline Sub 3 & 1.41 & 0.23 & 117 & 0.32 & 9 & 0.049 & 3.3 & 1076 \\
\hline Sub 4 & 1.16 & 0.26 & 117 & 0.31 & 11 & 0.026 & 2.9 & 1076 \\
\hline Sub 5 & 1.43 & 0.24 & 114 & 0.34 & 12 & 0.016 & 3.1 & 1083 \\
\hline Super & & 0.00 & 340 & 0.46 & 11 & 0.137 & 34 & 958 \\
\hline Matrix 1 & & 0.00 & 108 & 0.42 & 7 & 0.114 & 27 & 1042 \\
\hline Matrix 2 & & 0.00 & 249 & 0.47 & 10 & 0.060 & 31 & 945 \\
\hline
\end{tabular}

In order to accomplish this objective, the chemistry of the "matrix" was determined, and a new powder heat was prepared to this chemical composition. Yttria was added in order to control grain growth during super-solvus heat treatment. These "matrix alloys", with the composition listed in Table I, contained secondary and tertiary $\gamma^{\prime}$ particles, but no primary $\gamma^{\prime}$.

Table II summarizes the microstructures produced in this study. Grain sizes were determined by standard stereological procedures. Primary and secondary $\gamma^{\prime}$ sizes and fractions were determined by field emission scanning electron microscopy and stereology, while tertiary $\gamma^{\prime}$ sizes were determined by energy-filtered transmission electron microscopy. Details of the characterization techniques are presented in [1]. Tertiary $\gamma^{\prime}$ volume fractions were determined by subtracting the secondary and primary $\gamma^{\prime}$ fractions from the known equilibrium volume fractions. The microstructures denoted by "sub" were IN100 solutionized below the $\gamma^{\prime}$ solvus temperature, and therefore contained primary $\gamma^{\prime}$ particles and fine grain sizes. The microstructure denoted "super" was IN100 solutionized above the $\gamma^{\prime}$ solvus, which therefore contained no primary $\gamma^{\prime}$ and a large grain size. As explained above, the "matrix" alloys had the composition of the standard IN100 after subtracting the primary $\gamma^{\prime}$. The matrix alloys were super-solvus heat treated.

Also listed in the Table II heading row are the definitions of microstructural terms (in parentheses). For example, $d_{2}$ is the average diameter of the secondary $\gamma^{\prime}$ particles.

\section{The Constitutive Model}

Tensile tests were conducted on all eight microstructures using standard procedures, at $260^{\circ} \mathrm{C}$ and $650^{\circ} \mathrm{C}$. True stress vs true strain data from the tests were fit to a modified Ramberg-Osgood [2] monotonic constitutive model, according to the following form:

$$
\varepsilon=\left(\frac{\sigma}{E}\right)+\left(\frac{\sigma}{K}\right)^{n}
$$

$\mathrm{K}$ is a state variable usually referred to as the "Drag Stress", and is defined as:

$$
K=K_{1}+K_{2} e^{-m \varepsilon_{p}}
$$

where $\varepsilon_{\mathrm{p}}$ is the plastic strain. $\mathrm{K}_{2}$ and $\mathrm{m}$ define the curvature of the stress-strain graph at low plastic strains. As the plastic strain accumulates, the second term in Equation 2 begins to vanish. As such, $\mathrm{K}_{2}$ and $\mathrm{m}$ are only important in the small strain regime. As the second term in Equation 2 vanishes, Equation 1 reverts to the standard power-law hardening expression:

$$
\sigma=K_{1}\left(\varepsilon_{p}\right)^{1 / n}
$$

where $K_{1}$ is equivalent to the traditional $\mathrm{K}$ and $1 / \mathrm{n}$ is equivalent to the traditional $\mathrm{n}$.

The Ramberg-Osgood model was chosen because it is similar in form to the Pratt \& Whitney design constitutive model which is utilized in the rate-independent temperature regime. This simple uniaxial form does not need the "back stress" state variable which is necessary in the cyclic form. Trends in variations in the constants in this simple model are relevant to similar trends in the design constitutive model.

The tensile test data were fit to Equation 1 using the iSIGHT optimization program [3]. A combination of a genetic algorithm and traditional gradient-based techniques was used to minimize the difference in the accumulated strain between the actual data and the model curve predicted by Equation 1. After the curve fits had been optimized, the four model constants were recorded. Sensitivity studies were also conducted on the constants and on the predicted shapes of the curves. The variation in the constitutive constants as a function of microstructure was then studied via multiple linear regression analysis. 


\section{Results - Yield Strength}

Before trying to understand the variation in the constitutive constants as a function of microstructure, the yield strength was studied.

Simple correlations between microstructure and yield strength were not apparent. However, applying fundamental strengthening theories to the variation in the strength with microstructure was very successful. One model which has been applied to a wide variety of high volume fraction superalloys, with some success, is that of Huther and Reppich [4]. In their theory, the increment in critical resolved shear stress due to the presence of secondary $\gamma^{\prime}$ precipitates is:

$$
\Delta \tau=\frac{1}{2}\left[1.62 w\left(\frac{\Gamma}{b}\right)\left(\frac{G b}{d_{2}}\right) f_{2}\right]^{1 / 2},
$$

where $\Gamma$ is the antiphase boundary energy, $\mathbf{b}$ is the Burgers vector, $G$ is the shear modulus, $d_{2}$ is the diameter of secondary $\gamma^{\prime}$ particles, $f_{2}$ is the fraction of secondary $\gamma^{\prime}$ particles, and $\mathrm{w}$ is an adjustable parameter which arises due to elastic interaction between super-partial dislocations pairs which are shearing the microstructure. Equation 4 is valid in their so-called "strong pair cutting" regime, encompassing particle sizes above about $25 \mathrm{~nm}$. This is the regime in which both super-partials are contained within the same $\gamma^{\prime}$ precipitate. In the weak-pair cutting regime, in which the leading super-partial can shear the precipitate completely without the trailing super-partial entering the precipitate, the strength varies as $\mathrm{d}^{1 / 2}$.

Figure 2 shows a transmission electron micrograph of IN100 deformed at room temperature. Dislocation pairs are seen in the matrix, at the particle/matrix interface, verifying that the secondary precipitates are being sheared in the "strong pair cutting" regime; the pairs are not separated by $\gamma^{\prime}$ precipitates.

It is evident from Equation 3 that, for a given alloy system, variations in strength due to strong-pair cutting of precipitates should vary simply as:

$$
\Delta \sigma \propto\left[\frac{f_{2}}{d_{2}}\right]^{1 / 2}
$$

Simple linear regression fitting of the $260^{\circ} \mathrm{C}$ yield strength data vs $\mathrm{d}_{2}{ }^{-1 / 2}$ (Figure 3 ) demonstrates a reasonable correlation, with $\mathrm{R}^{2}=$ 0.83 . This indicates that the form of the Huther-Reppich model is a very good first approximation of the microstructural effect on strength, and that further, the secondary $\gamma^{\prime}$ size is a dominant term.

While the regression presented in Figure 3 is encouraging, it is not perfect. Trials with other microstructural parameters, as well as historical understanding at Pratt \& Whitney, indicated that there must be a Hall-Petch term (grain size strengthening). Further, the size of the tertiary $\gamma^{\prime}$ particles was found to correlate with the strength. Finally, according to Equation 5, the secondary $\gamma^{\prime}$ volume fraction is also relevant.

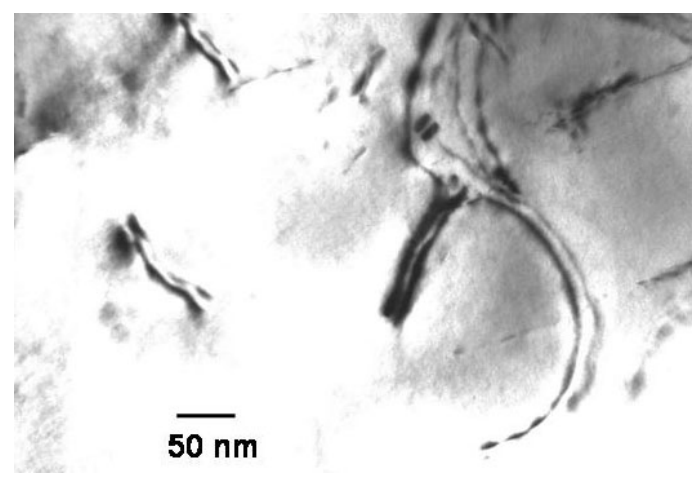

Figure 2. Transmission electron micrograph showing dislocation pairs in the interface between secondary $\gamma^{\prime}$ precipitates and the $\gamma$ matrix, indicative of "strong pair coupling", in which the super-partial pairs shear each precipitate in tandem. Room temperature deformation to approximately $2.5 \%$ strain, $\mathrm{g}=<111>$.

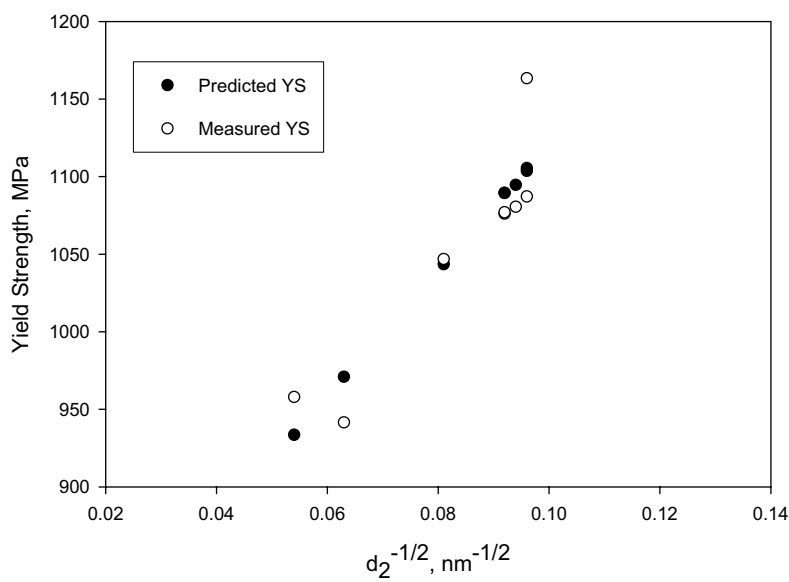

Figure 3. Simple, single linear regression of yield strength as a function of $\mathrm{d}_{2}^{-1 / 2}$ (with $\mathrm{d}_{2}$ in $\mathrm{nm}$ ) for all eight microstructures at $260^{\circ} \mathrm{C}$.

The most successful multiple linear regression fit of the $260^{\circ} \mathrm{C}$ yield strength data, which was also physically justifiable, was based on the following three variables:

- $\left[\frac{f_{2}}{d_{2}}\right]^{1 / 2}$ (strong pair cutting of secondary $\gamma^{\prime}$ )

- $\left[d_{3}\right]^{1 / 2}$ (weak pair cutting of tertiary $\gamma^{\prime}$ )

- $[G S]^{-1 / 2}$ (Hall-Petch strengthening)

Figure 4 shows the results of the regression, which had an $R^{2}$ value of 0.93 . The correlation between microstructure and yield strength at $650^{\circ} \mathrm{C}$ was similar. 
Table III- Ramberg-Osgood Constants at $260^{\circ} \mathrm{C}$

\begin{tabular}{|l|c|c|c|c|c|}
\hline \multicolumn{1}{|c|}{ Material } & $\begin{array}{c}\text { Yield Strength, } \\
\mathrm{MPa}\end{array}$ & $\mathrm{K}_{1}, \mathrm{GPa}$ & $\mathrm{K}_{2}, \mathrm{GPa}$ & $\mathrm{m}$ & $\mathrm{n}$ \\
\hline Sub 1 & 1165 & 3.52 & 5.78 & 66.6 & 2.93 \\
\hline Sub 2 & 1048 & 3.23 & 5.44 & 71.1 & 2.94 \\
\hline Sub 3 & 1076 & 3.34 & 6.01 & 70.2 & 2.90 \\
\hline Sub 4 & 1076 & 3.34 & 5.50 & 70.1 & 2.92 \\
\hline Sub 5 & 1083 & 3.25 & 5.32 & 72.0 & 3.00 \\
\hline Super & 958 & 2.88 & 4.41 & 69.6 & 3.00 \\
\hline Matrix 1 & 1042 & 3.30 & 6.65 & 56.5 & 2.76 \\
\hline Matrix 2 & 945 & 3.05 & 4.45 & 63.5 & 2.88 \\
\hline
\end{tabular}

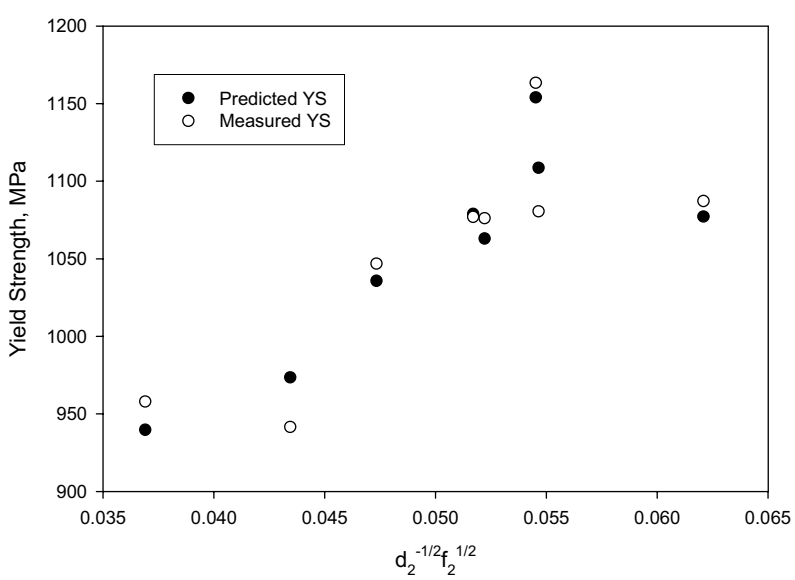

Figure 4. Multiple linear regression of yield strength for all eight microstructures at $260^{\circ} \mathrm{C}$. Regression was done against $\mathrm{d}_{2}{ }^{-1 / 2} \mathrm{f}_{2}{ }^{1 / 2}$ (representing strong pair cutting of secondary precipitates), $\mathrm{d}_{3}{ }^{1 / 2}$ (representing weak pair coupling of tertiary precipitates), and $\mathrm{GS}^{-1 / 2}$ (Hall-Petch strengthening). Plot shows correlation with strong pair cutting $\left(\mathrm{d}_{2}^{-1 / 2} \mathrm{f}_{2}^{1 / 2}\right)$ for convenience. $\mathrm{d}_{2}$ and $\mathrm{d}_{3}$ are in $\mathrm{nm}$.

\section{Results - Constitutive Constants}

Constitutive constants in the modified Ramberg-Osgood constitutive model (Equations 1, 2) were determined by optimization with iSIGHT. At least two tests were utilized at each condition, and multiple optimizations (at least five independent runs) were conducted to determine average values of the constants. The results are summarized in Table III.

It is evident from inspection of Table III that the constitutive constants varied substantially with microstructure. Before discussing linear regressions of individual constants as a function of microstructure, we now discuss sensitivity studies on the magnitudes of the constants.
Figure 5 shows true stress-strain curves for a typical test. Multiple curves are presented, with $\mathrm{K}_{2}$ varying by $\pm 20 \%$. It is evident from this figure that changes in $\mathrm{K}_{2}$ of this magnitude do not substantially affect the curve fit, except very close to yield.

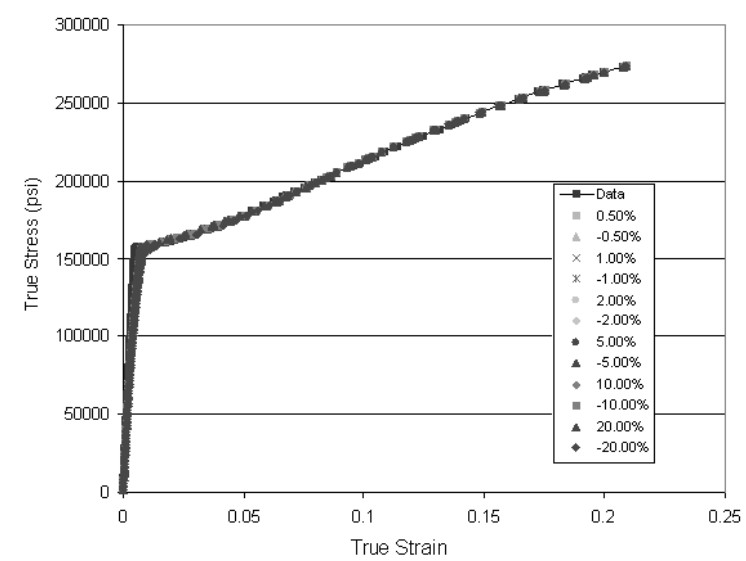

Figure 5. Sensitivity study on the Ramberg-Osgood constant $\mathrm{K}_{2}$, showing negligible effects on the ability to fit the tensile curve with changes in $K_{2}$ of $\pm 20 \%$.

Further, changes in $\mathrm{K}_{2}$ of about a factor of two did not have a substantial effect on the ability of the model to fit the tensile test data. The same was true of the constant $\mathrm{m}$. Therefore, it was concluded that the apparent microstructural sensitivity of the constants $\mathrm{K}_{2}$ and $\mathrm{m}$ was not significant.

On the other hand, much smaller changes in $\mathrm{K}_{1}$ and $\mathrm{n}$ had substantial effects on the curve fits. Figure 6 shows the sensitivity of the tensile test curve fits to $\mathrm{K}_{1}$, when it varies by only $5 \%$ (compared to $20 \%$ for $\mathrm{K}_{2}$ in Figure 5).

Therefore, it was determined that only two of the constants in the modified Ramberg-Osgood model $\left(\mathrm{K}_{1}\right.$ and $\left.\mathrm{n}\right)$ had a variation with microstructure that was significant. While the average values of $\mathrm{K}_{2}$ and $\mathrm{m}$ did vary with microstructure, the magnitude of the variation would have no practical effect on the ability of the model to fit the tensile test data. 
Based on this conclusion, regression analysis was conducted on the constitutive constants $\mathrm{K}_{1}$ and $\mathrm{n}$ for tensile tests at $260^{\circ} \mathrm{C}$. There was insufficient data at $650^{\circ} \mathrm{C}$ to conduct a study with the same rigor.

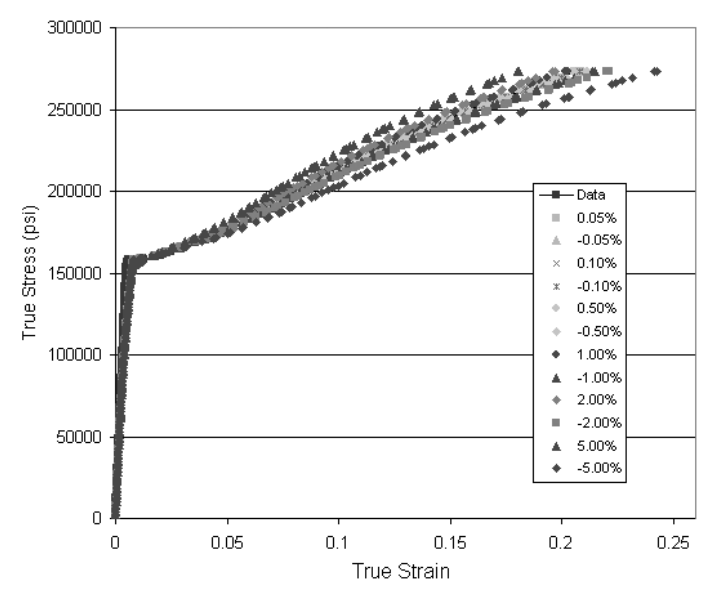

Figure 6. Sensitivity study on the Ramberg-Osgood constant $\mathrm{K}_{1}$, showing substantial effects on the ability to fit the tensile curve with changes in $\mathrm{K}_{1}$ of $\pm 5 \%$.

It was found that the microstructural variation of the "strength coefficient", $\mathrm{K}_{1}$, was exactly the same as the yield strength. That is, multiple linear regression analysis of $\mathrm{K}_{1} \mathrm{vs} \mathrm{d}_{2}{ }^{-1 / 2} \mathrm{f}_{2}{ }^{1 / 2}, \mathrm{~d}_{3}{ }^{1 / 2}$, and $\mathrm{GS}^{-1 / 2}$ resulted in an excellent fit. In fact, the fit was even better than that of the yield strength, with $\mathrm{R}^{2}=0.95$. The variation of $\mathrm{K}_{1}$ with the $\gamma^{\prime}$ particle parameters are again completely consistent with the Huther-Reppich precipitation hardening model, and the grain size term follows the Hall-Petch model. Figure 7 shows the fit, in a similar manner to Figure 4 for the yield strength.

The hardening exponent, $\mathrm{n}$, was slightly more complicated, because it was found that there was an effect of the primary $\gamma^{\prime}$ particles. Regression studies with many combinations of variables determined that the two microstructural parameters that correlated with strain hardening were the secondary $\gamma^{\prime}$ size and the presence of primary $\gamma^{\prime}$. The influence of secondary $\gamma^{\prime}$ particle size can be illustrated by considering the three microstructures that did not contain primary $\gamma^{\prime}$. Those microstructures were the two matrix alloys, and the super-solvus heat treated IN100. Figure 8 shows a simple, single linear regression of secondary $\gamma^{\prime}$ size vs the hardening exponent, $n$. There is an outstanding fit, with $\mathrm{R}^{2}=0.99$, over a fairly wide range of secondary $\gamma^{\prime}$ sizes (108 to $340 \mathrm{~nm}$ ).

Figure 8 demonstrates that $\mathrm{n}$ increased with particle size. Recalling that the exponent $\mathrm{n}$ in the modified Ramberg-Osgood constitutive model is the inverse of the traditional hardening exponent, and reviewing the functional form of Equation 1, this implies that larger secondary $\gamma^{\prime}$ particles result in decreased strain hardening. This will be discussed later in the paper.

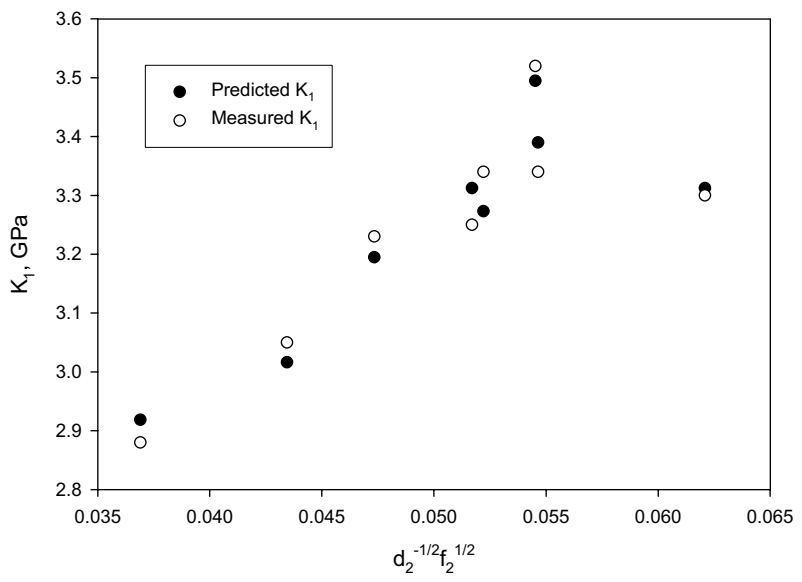

Figure 7. Multiple linear regression of the constitutive constant $\mathrm{K}_{1}$ for all eight microstructures at $260^{\circ} \mathrm{C}$. Regression was done against $\mathrm{d}_{2}^{-1 / 2} \mathrm{f}_{2}^{1 / 2}$ (representing strong pair cutting of secondary precipitates), $\mathrm{d}_{3}{ }^{1 / 2}$ (representing weak pair coupling of tertiary precipitates), and $\mathrm{GS}^{-1 / 2}$ (Hall-Petch strengthening). Plot shows correlation with $\mathrm{d}_{2}^{-1 / 2} \mathrm{f}_{2}^{1 / 2}$ for convenience. $\mathrm{d}_{2}$ and $\mathrm{d}_{3}$ are in $\mathrm{nm}$.

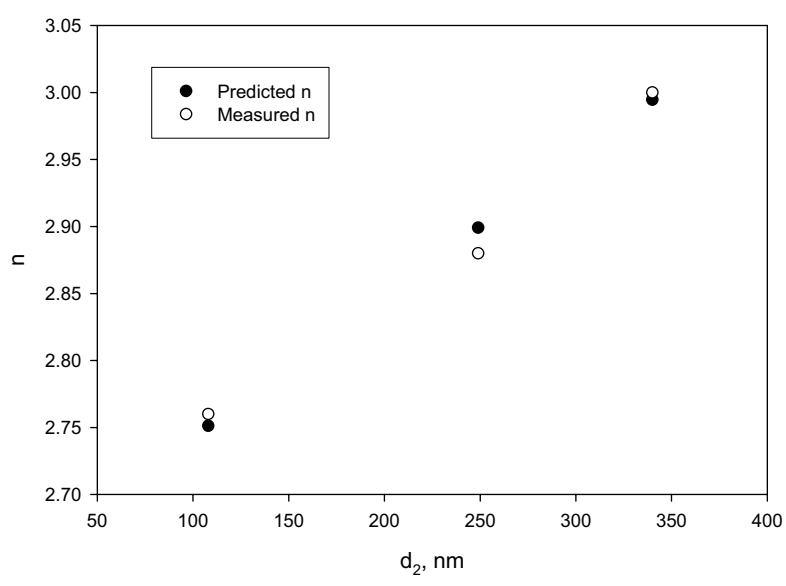

Figure 8. Simple, single linear regression of the constitutive constant $\mathrm{n}$ as a function of secondary $\gamma^{\prime}$ size, for the microstructures containing no primary $\gamma^{\prime}$, at $260^{\circ} \mathrm{C}$. 
Figure 9 shows a simple plot of secondary $\gamma^{\prime}$ size vs $\mathrm{n}$ for all eight microstructures. It is evident that the presence of primary $\gamma^{\prime}$ particles also decreases strain hardening.

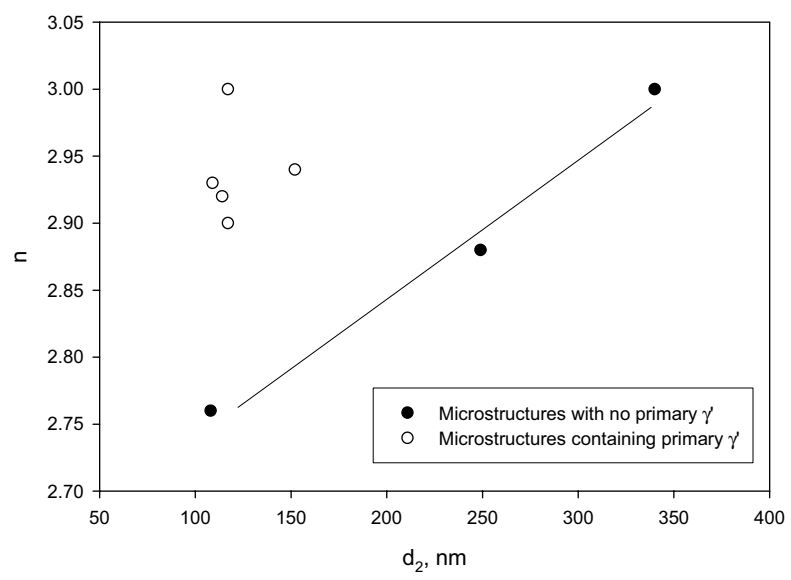

Figure 9. Plot of the constitutive constant $\mathrm{n}$ as a function of secondary $\gamma^{\prime}$ size for all eight microstructures at $260^{\circ} \mathrm{C}$.

In order to quantify the effects of the primary $\gamma^{\prime}$ particles on strain hardening, multiple linear regression analysis was conducted with different combinations of variables. As shown in Figure 8 , the secondary $\gamma^{\prime}$ size is clearly relevant to strain hardening. The best correlation, at $\mathrm{R}^{2}=0.90$, was found between $\mathrm{n}$ and both the secondary $\gamma^{\prime}$ size and primary $\gamma^{\prime}$ volume fraction. These results are presented in Figure 10. While not a perfect correlation, this seems to capture the trends in strain hardening reasonably well. Potential physical mechanisms are discussed later.

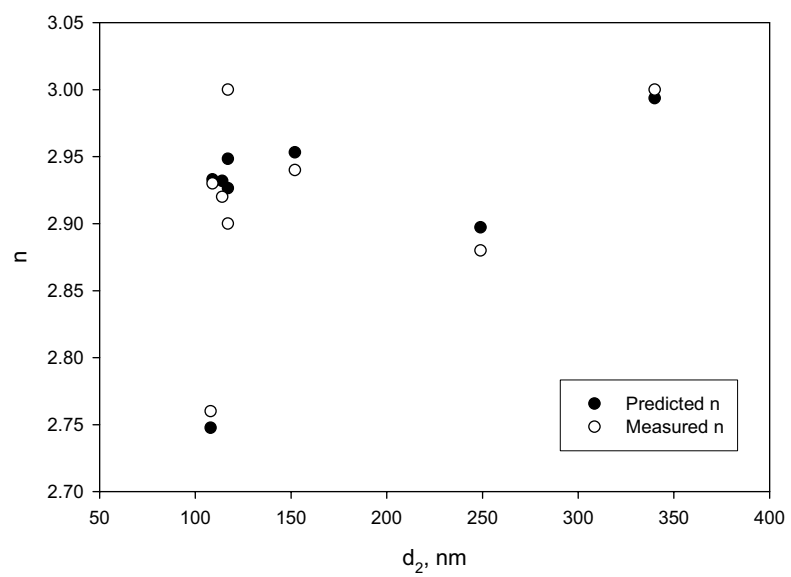

Figure 10. Multiple linear regression of the constitutive constant $\mathrm{n}$ for all eight microstructures at $260^{\circ} \mathrm{C}$. Regression was done against secondary $\gamma^{\prime}$ size and primary $\gamma^{\prime}$ volume fraction. Plot shows correlation with $\mathrm{d}_{2}$ for convenience.

\section{Discussion}

\section{Lack of Effect of Primary $\gamma^{\prime}$ on Yield Strength and $\mathrm{K}_{1}$}

One result from the regression was counter-intuitive; that is, the yield strength of the alloys (and the constitutive constant $\mathrm{K}_{1}$ ) did not correlate with primary $\gamma^{\prime}$ size or volume fraction. In order to further investigate this trend, nanoindentation studies were conducted on the standard sub-solvus alloy microstructure. Indentations were conducted with a Hysitron Triboscope, and standard procedures were utilized to estimate yield strength from the load-displacement data and the geometry of the indentations. A very fine tip was used to probe the primary $\gamma^{\prime}$, while a much coarser tip was utilized to obtain the "average" yield strength of the "matrix" material, which contained secondary and tertiary $\gamma^{\prime}$, as well as the $\gamma$ matrix.

A typical indentation is shown in Figure 11. The micrograph was constructed using the AFM scanning mode in the nanoindenter, and an indentation may be seen in one of the primary $\gamma^{\prime}$ precipitates. The secondary $\gamma^{\prime}$ precipitates are clearly delineated in the "matrix".

Results from the nanoindentation studies are presented in Figure 12. At the higher loads, after the results start to become insensitive to indentation force, it may be seen that the strength of the primary $\gamma^{\prime}$ particles is, within experimental error, indistinguishable from that of the two-phase "matrix". Thus, at approximately 25 percent (by volume) and with a strength similar to the matrix, it is reasonable that the primary $\gamma^{\prime}$ does not play a significant role in the microstructural effects on yield strength.

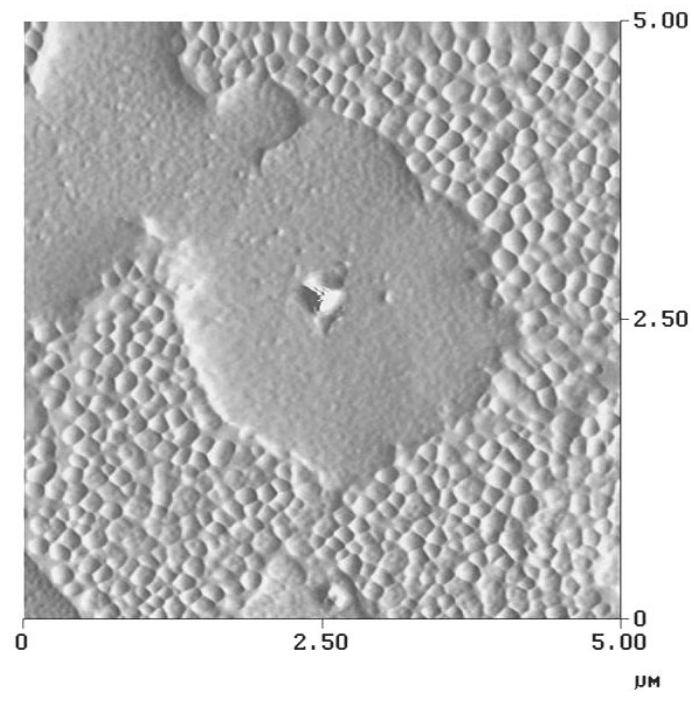

Figure 11. AFM scan showing nanoindentation in primary $\gamma^{\prime}$ particle, in the standard IN100 microstructure. Secondary $\gamma^{\prime}$ particles are visible in the "matrix". 


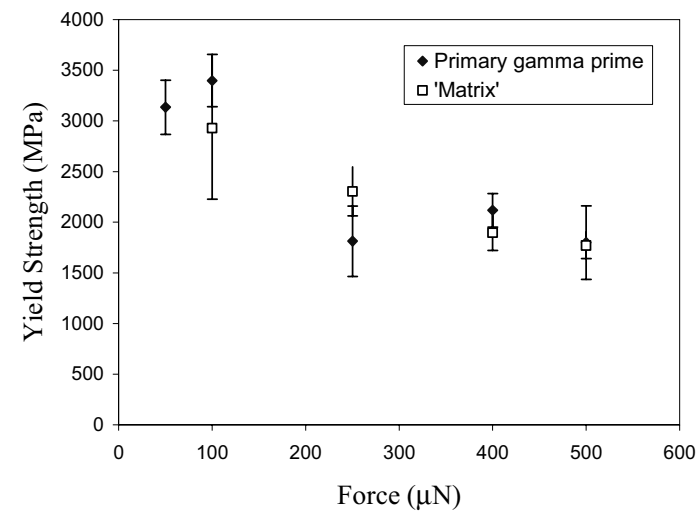

Figure 12. Yield strength as a function of indentation force, showing saturation above $250 \mu \mathrm{N}$. Within the significant experimental scatter of this technique, the strengths of the primary $\gamma^{\prime}$ particles and the twophase "matrix" are indistinguishable at $20^{\circ} \mathrm{C}$.

Transmission electron microscopy (TEM) was also utilized to study the deformation behavior of the primary $\gamma^{\prime}$ and the "matrix". If the strength of the primary $\gamma^{\prime}$ was significantly higher than the matrix, for example, one would not expect significant dislocation activity in the primary $\gamma^{\prime}$ particles at small strains.

Figure 13 shows a TEM micrograph of the standard IN100 microstructure which was deformed at room temperature. It is evident from Figure 13 that the primary $\gamma^{\prime}$ particles contained substantial dislocation debris after $2.5 \%$ strain, indicating that they were deforming along with the "matrix".

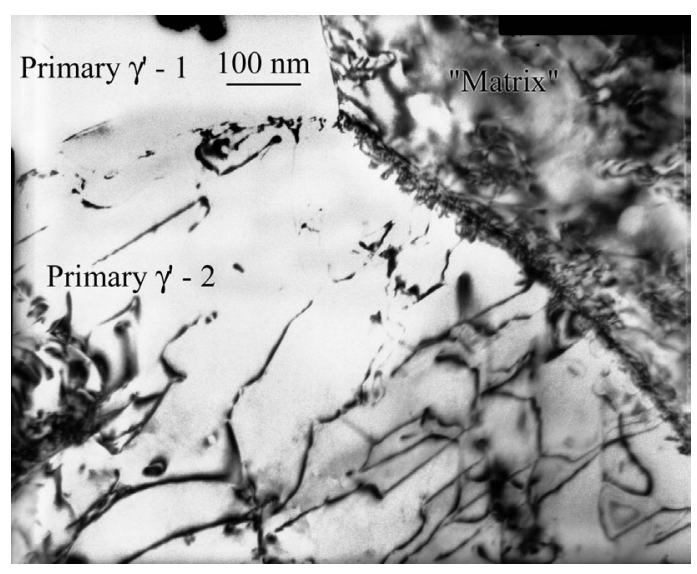

Figure 13. Transmission electron micrograph showing substantial deformation debris in the primary $\gamma^{\prime}$ particles after room temperature deformation to $2.5 \%$ plastic strain. $\mathbf{g}=<200>$.
In summary, all three techniques employed (regression, nanoindentation, TEM) supported the apparently counter-intuitive result that the primary $\gamma^{\prime}$ did not have a substantial effect on the variation in yield strength (or $\mathrm{K}_{1}$ ) with microstructure. However, at higher temperatures (where the anomalous strengthening of the $\gamma^{\prime}$ phase raises its flow stress), the primary $\gamma^{\prime}$ may have some effect on strength and K1. Further research is necessary.

\section{Lack of a Grain Size Effect on Strain Hardening}

While there was a small Hall-Petch effect on yield strength and $\mathrm{K}_{1}$, there was not a significant correlation between grain size and the hardening exponent, $\mathrm{n}$. While perhaps counter-intuitive, this is fully consistent with the results of a rigorous study of grain size effects on constitutive behavior in a single-phase nickel alloy. Gray, Chen and Vecchio [5] found that varying the grain size of Monel 400 from 9 to $200 \mu \mathrm{m}$ had a substantial effect on yield strength, but almost no effect on strain hardening.

\section{Microstructural Effects on Strain Hardening}

The conclusion that increasing secondary $\gamma^{\prime}$ size or adding primary $\gamma^{\prime}$ decreased strain hardening was also surprising. It has been known for almost 50 years $[6,7]$ that single-phase $\mathrm{Ni}_{3} \mathrm{Al}$ has a very rapid work hardening rate, which might imply that the presence of large, single crystalline primary $\gamma^{\prime}$ particles might lead to increased hardening instead of the observed decrease in hardening. Further, as the secondary $\gamma^{\prime}$ size increases, one might imagine a higher likelihood of Kear-Wilsdorf cross-slip locks inside the secondary $\gamma^{\prime}$ particles, which would lead to increased strain hardening. Neither of these was observed.

It is possible that both primary $\gamma^{\prime}$ particles and larger secondary $\gamma^{\prime}$ particles reduce strain hardening by promoting slip heterogeneity. Generally, more heterogeneous and planar dislocation processes lead to reduced strain hardening. At this point, the argument is speculative, and TEM studies of the deformation behavior are necessary. Such studies are currently in progress. 


\section{Microstructural Effects on Constitutive Constants}

Multiple linear regression analysis assumes a linear superposition of the effects of multiple mechanisms. For example, the yield strength in Figure 3 is assumed to be of the form:

$$
\sigma=\sigma_{o}+C_{1}\left\lfloor d_{2}^{-1 / 2} f_{2}^{1 / 2}\right\rfloor+C_{2}\left\lfloor d_{3}^{1 / 2}\right\rfloor+C_{3}\left[G S^{-1 / 2}\right] .
$$

Thus, while this is not a linear model due to the non-linear terms inside the brackets, the summation is linear. That is to say, the exponent on the bracketed terms and the yield strength is 1 .

As summarized recently by Sinharoy, Virro-Nic and Milligan [8], theoretical models of multiple strengthening mechanisms normally propose an exponent on each term varying between 1 and 2, depending on the relative magnitudes of the different effects. For example, adding the effects of precipitates and the matrix flow stress to obtain the strength of a superalloy, one would write:

$$
\sigma^{n}=\sigma_{\text {matrix }}^{n}+[f(d, f, \Gamma)]^{n}
$$

where $\sigma$ is the yield strength of the alloy, $\sigma_{\text {matrix }}$ is the flow stress of the matrix, $f(\mathrm{~d}, \mathrm{f}, \Gamma)$ is the form of the precipitation hardening term as a function of particle size, volume fraction, and antiphaseboundary energy, and $\mathrm{n}$ is a semi-empirical exponent which varies between 1 and 2. For superalloys, limited studies available in the literature (summarized in [8]) have found the exponent to be around 1.1, which is fairly close to 1 . Based on this and the complexity of the problem, linear superposition appears to be a completely reasonable approach.

Based on this linear superposition of the important variables described earlier and the regressions, one may write equations for the constitutive constants of IN100-type alloys at $260^{\circ} \mathrm{C}$.

For the yield strength at $260^{\circ} \mathrm{C}$ :

$$
\sigma=495+6765\left[d_{2}^{-1 / 2} f_{2}{ }^{1 / 2}\right]+52.3\left[d_{3}{ }^{1 / 2}\right]+105\left[G S^{-1 / 2}\right] \mathrm{MPa},
$$

with $d_{2}$ and $d_{3}$ in $n m$ and the grain size in $\mu \mathrm{m}$. For the constitutive constant $\mathrm{K}_{1}$ at $260^{\circ} \mathrm{C}$ :

$$
K_{1}=1.75+18.7\left[d_{2}{ }^{-1 / 2} f_{2}{ }^{1 / 2}\right]+0.126\left[d_{3}{ }^{1 / 2}\right]+0.31\left[G S^{-1 / 2}\right] \mathrm{GPa},
$$

again, with $\mathrm{d}_{2}$ and $\mathrm{d}_{3}$ in $\mathrm{nm}$ and the grain size in $\mu \mathrm{m}$. For the constitutive constant $\mathrm{n}$ at $260^{\circ} \mathrm{C}$ :

$$
n=2.63+1.06 \times 10^{-3}\left[d_{2}\right]+0.73\left[f_{1}\right]
$$

with $d_{2}$ in $\mathrm{nm}$. As mentioned earlier, the constitutive constants $\mathrm{K}_{2}$ and $\mathrm{m}$ are not sensitive to microstructure and have small effects on the curves, so their approximate average values can be used:

$$
\mathrm{K}_{2}=5.5 \mathrm{GPa} ; \quad \mathrm{m}=70
$$

A plot of the predicted vs actual yield strength at $260^{\circ} \mathrm{C}$, based on Equation 7, is presented in Figure 14(a). The largest residual is 31 $\mathrm{MPa}$, about $4.5 \mathrm{ksi}$. Figures 14 (b) and (c) show similar plots for $\mathrm{K}_{1}$ and $\mathrm{n}$. Considering the wide range of microstructures and constitutive constant values, the fits appear to be quite reasonable.
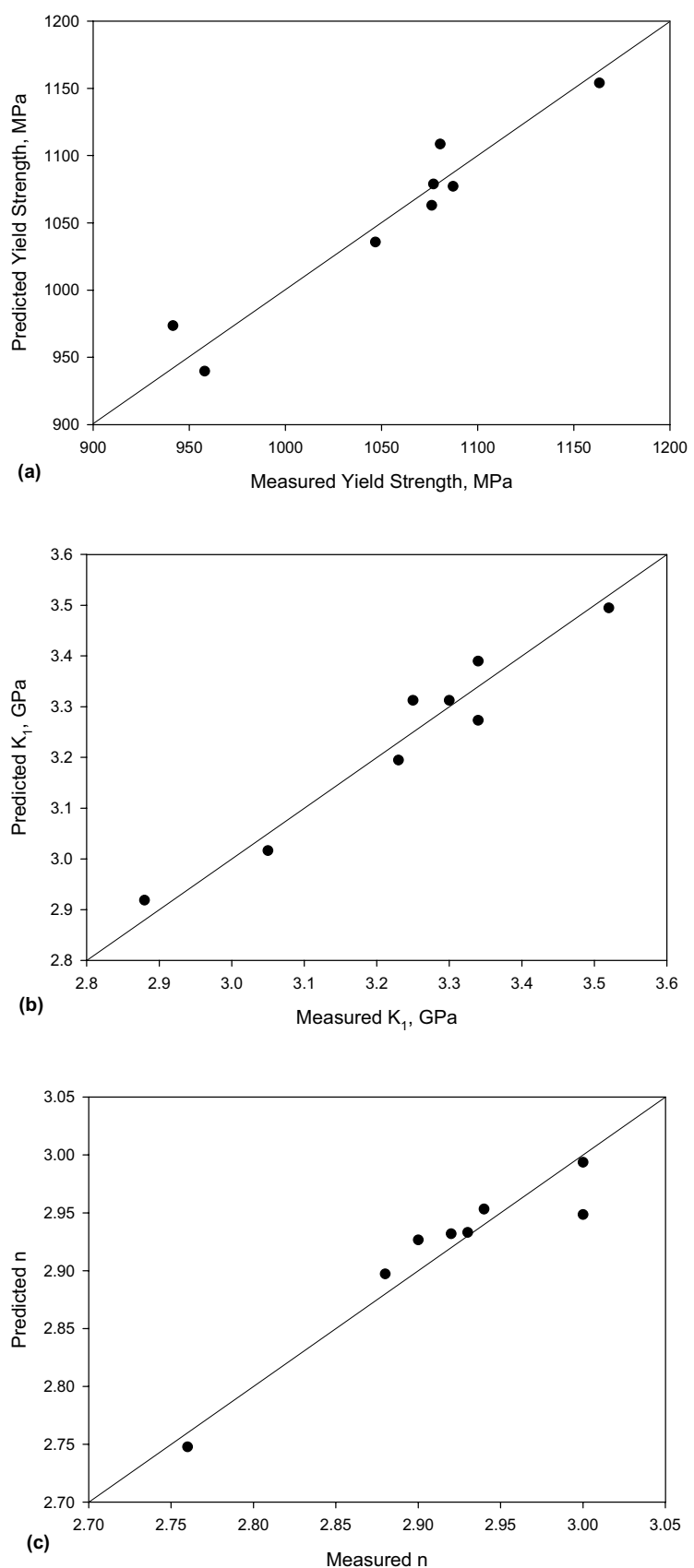

Figure 14. Measured constitutive constants vs predicted constants for all eight microstructures at $260^{\circ} \mathrm{C}$. 


\section{Conclusions}

It is possible to determine the microstructural sensitivity of constitutive model constants for monotonic loading of nickel-base superalloys at elevated temperatures. For alloys based on IN100, a modified Ramberg-Osgood model (incorporating four constants) works well. Only two of the constants are sensitive to microstructure. The strength coefficient, $\mathrm{K}_{1}$, varies with microstructure in exactly the same manner as the yield strength. Consistent with the Huther-Reppich strength model, these material parameters are a function of secondary and tertiary $\gamma^{\prime}$ fractions and size distributions. There is also a Hall-Petch term. The hardening exponent, $\mathrm{n}$, is affected by the secondary $\gamma^{\prime}$ size and the primary $\gamma^{\prime}$ volume fraction, but not the grain size. Predictions of the constitutive constants as a function of microstructure, based on linear superposition, are in reasonable agreement with the data at $260^{\circ} \mathrm{C}$.

\section{Acknowledgements}

This research was supported by the DARPA Accelerated Insertion of Materials Program, Cooperative Agreement F33615-00-2-5216 with Pratt and Whitney, which was monitored by Dr. Leo Christodoulou (DARPA) and Dr. Rollie Dutton (AFRL). We thank Dr. Martin Blackburn and Dr. Mark Aindow of the University of Connecticut for the materials characterization data, and Dr. William Gerberich of the University of Minnesota for the nanoindentation collaboration. We are grateful to Mr. Ryan Thompson (now at Kodak) for some of the experimental work.

\section{References}

1. A.M. Wusatowska-Sarnek, M.J. Blackburn and M. Aindow, "Techniques for Microstructural Characterization of PowderProcess Nickel-based Superalloys", Mater. Sci. Engng. A, 360 (2003), 390-395.

2. W. Ramberg and W.R. Osgood, "Determination of StressStrain curves by Three Parameters", Technical Note No. 503, National advisory Committee on Aeronautics (NACA), 1941.

3. iSIGHT optimization program, Engineous Software Company, Cary, NC, http://www.engineous.com/index.htm

4. W. Huther and B. Reppich, "Interaction of Dislocations with Coherent, Stress-Free Ordered Particles", Z. Metallkd., 19 (1978), 628-634.

5. G.T. Gray, S.R. Chen and K.S. Vecchio, "Influence of grain size on the constitutive response and substructure evolution of Monel 400”, Metall. Mater. Trans. A, 30A (1999), 1235-1247.

6. P.A. Flinn, "Theory of Deformation in Superlattices", Trans. TMS-AIME, 218 (1960), 145-154.

7. P.H. Thornton, R.G. Davies and T.L. Johnston, "The Temperature Dependence of the Flow Stress of the $\gamma^{\prime}$ phase Based upon $\mathrm{Ni}_{3} \mathrm{Al}$ ”, Metall. Trans., 1 (1970), 207-218.

8. S. Sinharoy, P. Virro-Nic and W.W. Milligan, "Deformation and Strength Behavior of Two Nickel-Base Turbine Disk Alloys at $650^{\circ} \mathrm{C}^{\prime}$, Metall. Mater. Trans. A, 32A (2001), 2021-2032. 
